\title{
Research on reservoir bed heterogeneity, interlayers and seal layers and controlling factors of $2+3$ sands of upper second member, Shahejie Formation, in the west of the Pucheng Oilfield
}

\author{
Zhang Wei ${ }^{1}$, Zhang Jinliang ${ }^{1,2}$ * and Xie Jun ${ }^{1}$ \\ ${ }^{1}$ College of Marine Geo-Science, Ocean University of China, Qingdao, Shandong 266100, China \\ ${ }^{2}$ College of Resource Science and Technology, Beijing Normal Unicersity, Beijing 100875, China
}

\begin{abstract}
Terminal fans have formed the sedimentary system of the 2+3 sands of the upper second member, Shahejie formation in the west of the Pucheng Oilfield, Bohai Bay Basin, East China. Based on well logging data and physical properties of the reservoir beds, the $2+3$ sands were divided into 16 sublayers. The heterogeneity of reservoir beds and distribution of interlayers and seal layers in the $2+3$ sands were investigated. The intra-layer heterogeneity and inter-layer heterogeneity primarily belong to the severely heterogeneous classification. The spatial differentiation of sedimentary microfacies resulted in a change of reservoir bed heterogeneity, strong in the middle and southern parts, weak in the northern part. Spatial distribution of interlayers and seal layers is dominated by sedimentary microfacies, and they are thick in north-eastern and middle parts, thin in the south-western part.
\end{abstract}

Key words: Sedimentary system, terminal fan, reservoir bed heterogeneity, interlayer and seal layer

\section{Introduction}

The Dongpu Sag is a secondary unit of the Linqing Depression in the Bohai Bay Basin, East China, extending in the NNE direction; the area is about 5,300 square kilometers. The Pucheng Oilfield is located in the north of the Dongpu Sag (Fig. 1). Regionally it is positioned in the north of the central uplift belt of the Dongpu Sag. The Pucheng structure is an inherited structure uplifted from the low-lying land, and its structural configuration is a long-axis anticline complicated by faults, 15 kilometers in the north-south orientation, and 4.5 kilometers in the east-west orientation.

The Dongpu Sag is a rifted basin developed in the late stage of the Yanshan Movement in the late Mesozoic, and the ascending order of stratigraphic sequence is Archean, Paleozoic, Mesozoic, and Cenozoic. The Cenozoic is divided into Paleogene, Neogene, and Quaternary. The second member of the Shahejie Formation, Paleogene is the major oil-bearing formation in the Pucheng Oilfield, developed in the fluvial-terminal fan deposit in the shore-shallow lake environment (Stanistreet and McCathy, 1993). It can be subdivided into upper second member and lower second member. The upper second member can be further divided into seven sand layers, sands 1 to 7 . The sands $1+3$ are mainly medium to thin siltstone frequently interbedded with grayish green and

* Corresponding author. email: jinliang@ires.cn

Received April 1, 2007

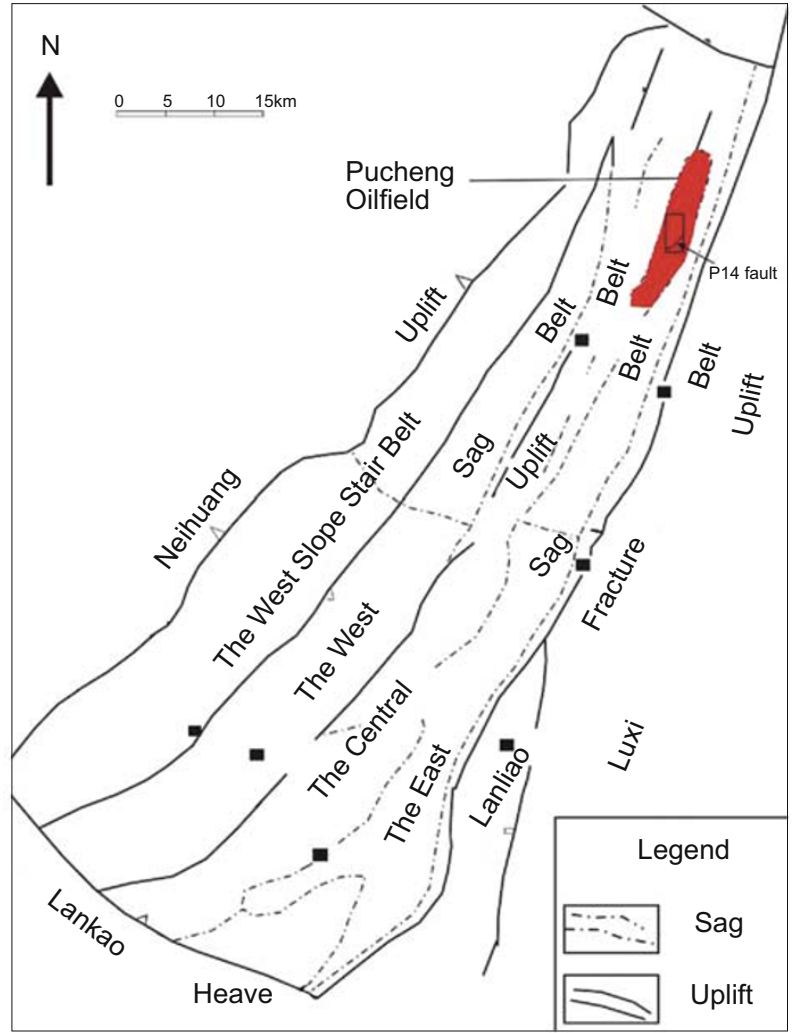

Fig. 1 Location of Pucheng Oilfield and the study block 
light brown mudstone and sandy mudstone. The sands $4+7$ are lenticular fine sandstone, interbedded with grayish-green, grayish yellow and light brown mudstone (Fig. 2). In these seven sand layers, the sands $2+3$ were the target of this study. According to the cycle of sedimentation and oil-bearing features, the sand 2 was further divided into 7 sub-layers and the sand 3 was further divided into 9 sub-layers. The stratigraphic column of Cenozoic formations in the Pucheng Oilfield is shown in Fig.2.

The $2+3$ sands were mainly developed on the margin of the overspreading-shrinking lake basin. During the sedimentary period of the sand 3 , sediments prograded towards the lake basin, with the supply of sediments from the Luxi Uplift. The deposits were mainly gray and light brown mudstone interbedded with silty sandstone. At the sedimentary time of the sand 2 , sediments retrograded towards the land, with the supply of sediments also from the Luxi Uplift, but the hydraulic conditions of this time weakened compared with the sand 3 , so the size and total thickness of sand bodies were smaller. The deposits were also mainly gray mudstone and silty sandstone.

\section{The research materials and methods}

\subsection{Reservoir bed heterogeneity of $2+3$ sands, upper second member, Shahejie Formation}

Porosity, permeability and porous structure are fundamental parameters measuring the capability of preserving and transporting fluids in the formation rocks (Liu et al, 2001). Porosity controls the amount of fluids preserved, additionally, permeability controls the oil/gas productivity in the reservoir bed. The lithologic properties of reservoir bed are not homogeneous, and they are mainly determined by the sedimentary environment. Sedimentary environments are not the same, and the types of heterogeneity are different. Reservoir bed heterogeneity can be represented by the porosity, permeability, and thickness of sand bodies, as well as the distribution of interlayers and seal layers. Reservoir bed heterogeneity controls the distribution, accumulation and productivity of oil/gas (Zhang and Chang, 2004).

Here, the heterogeneity of the sands $2+3$ was studied from three aspects: intra-layer heterogeneity, inter-layer

\begin{tabular}{|c|c|c|c|c|c|c|c|c|c|}
\hline \multicolumn{4}{|c|}{ Stratgraphic sequence } & \multirow[b]{2}{*}{ Menber } & \multirow[b]{2}{*}{ Code } & \multirow{2}{*}{$\begin{array}{c}\text { Thickness } \\
\mathrm{m}\end{array}$} & \multirow{2}{*}{$\begin{array}{l}\text { Litho- } \\
\text { logical } \\
\text { charac- } \\
\text { teristics }\end{array}$} & \multirow[b]{2}{*}{ Lithological characteristics } & \multirow[b]{2}{*}{ Sedimentary facies } \\
\hline Erathem & Subsystem & Series & Formation & & & & & & \\
\hline \multirow{6}{*}{ 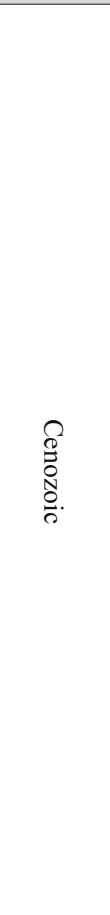 } & \multirow{6}{*}{ 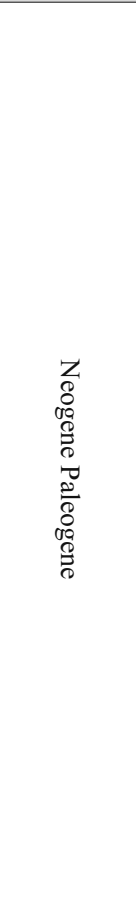 } & \multirow{3}{*}{ 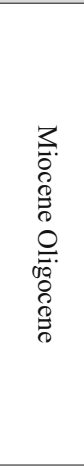 } & \multirow{6}{*}{ 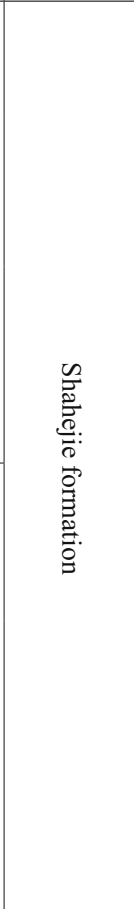 } & $\begin{array}{l}\text { Upper first } \\
\text { member }\end{array}$ & $\mathrm{Es}_{\mathrm{I}}^{\mathrm{U}}$ & $\begin{array}{c}100 \\
\mid \\
200\end{array}$ & 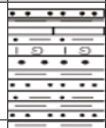 & $\begin{array}{l}\text { Mainly grey, deep grey mudstone and } \\
\text { silt, sandstone, containing limestone }\end{array}$ & $\begin{array}{l}\text { Shallow-medium } \\
\text { deep lacustrine } \\
\text { facies }\end{array}$ \\
\hline & & & & $\begin{array}{c}\text { Lower first } \\
\text { member }\end{array}$ & $\mathrm{Es}_{\mathrm{I}}^{\mathrm{L}}$ & $\begin{array}{c}50 \\
\mid \\
400\end{array}$ & 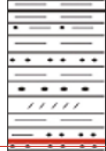 & $\begin{array}{l}\text { Mainly grey, deep grey mudstone } \\
\text { containing halolite }\end{array}$ & Delta facies \\
\hline & & & & $\begin{array}{l}\text { Upper second } \\
\text { member }\end{array}$ & $\mathrm{Es}_{2}^{\mathrm{U}}$ & $\begin{array}{c}120 \\
600\end{array}$ & 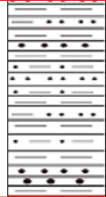 & $\begin{array}{l}\text { It can be divided into } 7 \text { sands, brown } \\
\text { mudstone, interbedding thinner silty } \\
\text { sandstone in } 1+3 \text { sands; grey mudstone } \\
\text { interbedding sandstone in } 4+7 \text { sands }\end{array}$ & $\begin{array}{l}\text { Terminal fan shore- } \\
\text { shallow lacustrine } \\
\text { facies }\end{array}$ \\
\hline & & \multirow{3}{*}{$\begin{array}{l}\Gamma \\
0 \\
0 \\
0 \\
0\end{array}$} & & $\begin{array}{c}\text { Lower second } \\
\text { member }\end{array}$ & $\mathrm{Es}^{\mathrm{L}}{ }_{2}$ & $\begin{array}{c}240 \\
\mid \\
550\end{array}$ & 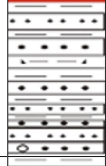 & $\begin{array}{l}\text { Mainly purplish red, light brown } \\
\text { mudstone and grey sandstone containing } \\
\text { carbonate sandstone }\end{array}$ & $\begin{array}{l}\text { Fluvial-flood plain } \\
\text { faices }\end{array}$ \\
\hline & & & & $\begin{array}{l}\text { Upper third } \\
\text { member }\end{array}$ & $\mathrm{Es}_{3}^{\mathrm{U}}$ & $\begin{array}{c}100 \\
600\end{array}$ & 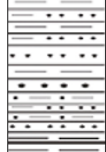 & $\begin{array}{l}\text { Mainly grey, deep grey mudstone } \\
\text { interbedding silty sandstone, the upper } \\
\text { part of which are calcareous sand or } \\
\text { sagstone }\end{array}$ & $\begin{array}{l}\text { M e di u m d e e p - } \\
\text { deep salt lacustrine } \\
\text { facies }\end{array}$ \\
\hline & & & & $\begin{array}{l}\text { Middle third } \\
\text { member }\end{array}$ & $\mathrm{Es}_{3}^{\mathrm{M}}$ & $\begin{array}{c}300 \\
1 \\
500\end{array}$ & 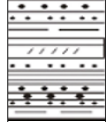 & $\begin{array}{l}\text { Mainly deep grey schist, halolite and } \\
\text { silty sandstone }\end{array}$ & $\begin{array}{l}\text { Delta, turbidity and } \\
\text { fan-delta facies }\end{array}$ \\
\hline
\end{tabular}

Fig. 2 Stratigraphic column of Cenozoic formations in Pucheng Oilfield (study sands in red frame)

heterogeneity and spatial heterogeneity (Xia et al, 1999).

\subsection{Interlayers and seal layers of $2+3$ sands, upper second member, Shahejie Formation}

Seal layer or barrier is the impermeable rock which can stop or restrict the flow of fluid, and its area is larger than half of the flow unit ( $\mathrm{Li}$ and $\mathrm{Li}, 2003$ ). Its thickness varies between centimeters and meters. The interlayer is the relatively impermeable sub-layers in the sand body, which can not restrict the fluid flow completely, and their area is often smaller than half of the flow unit. Their thickness is often between several centimeters and tens of centimeters, and their their seal properties are inferior to seal layer (Zhou and $\mathrm{Li}, 2001$ ).

Observation of the core samples of the sands $2+3$ from multiple cored wells, and the data of well-logging, e .g. SP, 
MR, and GR indicated that the interlayer could be classified into three types: muddy interlayer, silty sand interlayer and calcareous cemented interlayer and the seal layer could be classified into three types: uniformly distributed seal layer, streak-like distributed seal layer and fragmentary seal layer.

\section{Results}

\subsection{Reservoir bed heterogeneity of $2+3$ sands, upper second member, Shahejie Formation}

\subsubsection{Intra-layer heterogeneity}

Intra-layer heterogeneity is defined as the variation of reservoir bed physical properties in the vertical direction in a single sand body. It reflects the overall degree of heterogeneity in terms of physical properties, and can be described by several fundamental parameters below ( $\mathrm{Ji}$, et al, 2007).

1) Differential Jk (Jmax/Jmin): the ratio of the maximum and minimum of permeability; the larger the ratio, the stronger the heterogeneity.

2) Breakthrough coefficient $\mathrm{Tk}(\mathrm{kmax} / \mathrm{k})$ : the ratio of the maximum and mean of permeability. When Tk is less than 2 , the layer is homogeneous. When Tk is between 2 and 3, the layer is fairly homogeneous. When Tk is greater than 3 , the layer is heterogeneous.

3) Coefficient of homogeneity $\mathrm{Kk}(\mathrm{k} / \mathrm{kmax})$ : It is the reciprocal of the breakthrough coefficient, which varies form 0 to 1 . When it is close to 1 , the layer is homogeneous.

4) Coefficient of variation $\mathrm{Vk}(\sigma \mathrm{k} / \mathrm{k})$ : The ratio of the standard deviation and mean of permeability. When $\mathrm{Vk}$ is less than 0.5 , the layer is homogeneous. When Vk is between 0.5 and 0.7 , the layer is fairly homogeneous. When $\mathrm{Vk}$ is greater than 0.7 , the layer is heterogeneous.

$\mathrm{Jk}, \mathrm{Tk}, \mathrm{Kk}$ and $\mathrm{Vk}$ values of sub-layers of the $2+3$ sands are shown in Table 1 . In the sand 2, maximum $\mathrm{Jk}$ is 3944.5 , and minimum $\mathrm{Jk}$ is 132.68 ; maximum $\mathrm{Tk}$ is 8.3 , and minimum Tk is 4.23 ; maximum $\mathrm{Vk}$ is 2.75 , and minimum $\mathrm{Vk}$ is 0.8 .In the sand 3, maximum $\mathrm{Jk}$ is 1281.14 , and minimum $\mathrm{Jk}$ is 233 ; maximum $\mathrm{Tk}$ is 5.87 , and minimum $\mathrm{Jk}$ is 2.25 , maximum $\mathrm{Vk}$ is 1.35 , and minimum $\mathrm{Vk}$ is 0.58 .

Because the coefficient of homogeneity is the reciprocal of the breakthrough coefficient, so in the discussions, it is enough to use one of them, and we will use breakthrough

Table 1 Heterogeneity parameters of each sub-layer of $2+3$ sands

\begin{tabular}{|c|c|c|c|c|c|c|c|}
\hline Sub-layer & $\begin{array}{c}\text { Maximum } \\
10^{-3} \mu^{2}\end{array}$ & $\begin{array}{c}\text { Minimum } \\
10^{-3} \mu^{2}\end{array}$ & $\begin{array}{l}\text { Mean } \\
10^{-3} \mu \mathrm{m}^{2}\end{array}$ & Differential & $\begin{array}{c}\text { Breakthrough } \\
\text { Coefficient }\end{array}$ & $\begin{array}{l}\text { Coefficient of } \\
\text { homogeneity }\end{array}$ & $\begin{array}{l}\text { Coefficient of } \\
\text { variation }\end{array}$ \\
\hline 0201 & 276.11 & 0.07 & 33.26 & 3944.5 & 8.3 & 0.12 & 2.75 \\
\hline 0202 & 185.78 & 0.14 & 27.19 & 1327 & 6.83 & 0.146 & 1.98 \\
\hline 0203 & 287.6 & 0.25 & 61.59 & 1173.86 & 4.67 & 0.214 & 0.84 \\
\hline 0204 & 334.36 & 0.28 & 25.5 & 1194.13 & 5.53 & 0.181 & 1.11 \\
\hline 0205 & 334.36 & 0.18 & 48.3 & 1910.6 & 6.92 & 0.145 & 1.50 \\
\hline 0206 & 334.36 & 2.52 & 64.55 & 132.68 & 5.18 & 0.193 & 0.82 \\
\hline 0207 & 314.55 & 0.35 & 73.39 & 898.7 & 4.23 & 0.236 & 0.80 \\
\hline 0301 & 334.36 & 0.32 & 85.2 & 1061.44 & 3.92 & 0.255 & 0.83 \\
\hline 0302 & 371.5 & 0.29 & 89.48 & 1271.37 & 4.15 & 0.241 & 0.82 \\
\hline 0303 & 299.18 & 0.32 & 69.83 & 949.778 & 4.28 & 0.234 & 0.89 \\
\hline 0304 & 334.36 & 0.46 & 77.21 & 734.85 & 4.33 & 0.231 & 0.799 \\
\hline 0305 & 281.54 & 0.63 & 73.6 & 446.89 & 3.83 & 0.261 & 0.83 \\
\hline 0306 & 334.36 & 0.385 & 66.29 & 868.45 & 5.04 & 0.198 & 1.06 \\
\hline 0307 & 334.36 & 1.44 & 148.86 & 233 & 2.25 & 0.444 & 0.58 \\
\hline 0308 & 313.88 & 0.25 & 53.32 & 1281.14 & 5.87 & 0.17 & 1.05 \\
\hline 0309 & 202.58 & 0.385 & 40.17 & 526.18 & 5.04 & 0.198 & 1.35 \\
\hline
\end{tabular}


coefficient here. Based on the generally accepted criteria for classifying heterogeneity (Table 2), the breakthrough coefficients of seven sub-layers in the sand 2 are all greater than 3 , coefficients of variation are all greater than 0.7 , so the sand 2 is severely heterogeneous. In the sand 3 , coefficients of variation of 9 sub-layers are greater than 0.7 except the ninth sub-layer, coefficients of heterogeneity are greater than 3 except the seventh sub-layer, so the sand 3 is also severely heterogeneous. From those data, we consider that the intralayer heterogeneity of the $2+3$ sands obviously belongs to the type of severely heterogeneous.

Table 2 Criteria accepted generally for classifying reservoir bed heterogeneity

\begin{tabular}{c|c|c|c}
\hline $\begin{array}{c}\text { Type of } \\
\text { heterogeneity }\end{array}$ & $\begin{array}{c}\text { Boundary value } \\
\text { of coefficient of } \\
\text { variation }\end{array}$ & $\begin{array}{c}\text { Boundary value of } \\
\text { coefficient of } \\
\text { homogeneity }\end{array}$ & $\begin{array}{c}\text { Boundary value } \\
\text { of breakthrough } \\
\text { coefficient }\end{array}$ \\
\hline $\begin{array}{c}\text { Relatively } \\
\text { heterogeneous type }\end{array}$ & $<0.5$ & $>0.5$ & $<2.0$ \\
Heterogeneous type & $0.5-0.7$ & $0.33-0.5$ & $2.0-3.0$ \\
$\begin{array}{c}\text { Severely } \\
\text { heterogeneous type }\end{array}$ & $>0.7$ & $<0.33$ & $>3.0$ \\
\hline
\end{tabular}

\subsubsection{Inter-layer heterogeneity}

Inter-layer heterogeneity represents the variations of reservoir bed physical properties between sub-layers in the vertical direction, including cycle of sequences, variation of permeability of sub-layers, and distribution of seal layer (Qin and Zhang, 2007).

Some parameters can reflect the inter-layer heterogeneity of reservoir beds, such as the coefficient of variation, breakthrough coefficient, drill-in ratio of seal layer.

Based on the analysis of data from 273 production wells in the western part (Table 3, Table 4), in the sand 2, maximum breakthrough coefficient is 8.3 , and minimum breakthrough coefficient is 4.23 ; maximum coefficient of variation is 2.75 , and minimum coefficient of variation is 0.8 ; maximum drillin ratio of seal layer is $82.4 \%$, and minimum drill-in ratio of seal layer is $59.2 \%$. In the sand 3, maximum breakthrough coefficient is 5.87 , and minimum breakthrough coefficient is 2.25; maximum coefficient of variation is 1.35 , and minimum coefficient of variation is 0.58 ; maximum drillin ratio of seal layer is $77.3 \%$, and minimum drill-in ratio of seal layer is $59.2 \%$. According to the criteria for classifying heterogeneity (Table 2), the inter-layer heterogeneity of the $2+3$ sands belongs to the type of heterogeneous or severely heterogeneous.

Table 3 Statistical data of inter-layer heterogeneity of $2+3$ sands, upper second member, Shahejie Formation

\begin{tabular}{|c|c|c|c|}
\hline Sub-layers & Differential & $\begin{array}{c}\text { Breakthrough } \\
\text { coefficient }\end{array}$ & $\begin{array}{c}\text { Coefficient of } \\
\text { variation }\end{array}$ \\
\hline 0201 & 3944.5 & 8.3 & 2.75 \\
\hline 0202 & 1327 & 6.83 & 1.98 \\
\hline 0203 & 1173.86 & 4.67 & 0.84 \\
\hline 0204 & 1194.13 & 5.53 & 1.11 \\
\hline 0205 & 1910.6 & 6.92 & 1.50 \\
\hline 0206 & 132.68 & 5.18 & 0.82 \\
\hline 0207 & 898.7 & 4.23 & 0.80 \\
\hline 0301 & 1061.44 & 3.92 & 0.83 \\
\hline 0302 & 1271.37 & 4.15 & 0.82 \\
\hline 0303 & 949.778 & 4.28 & 0.89 \\
\hline 0304 & 734.85 & 4.33 & 0.799 \\
\hline 0305 & 446.89 & 3.83 & 0.83 \\
\hline 0306 & 868.45 & 5.04 & 1.06 \\
\hline 0307 & 233 & 2.25 & 0.58 \\
\hline 0308 & 1281.14 & 5.87 & 1.05 \\
\hline 0309 & 526.18 & 5.04 & 1.35 \\
\hline
\end{tabular}

Table 4 Drill-in ratio of seal layers in 2+3 sands, upper second member, Shahejie Formation

\begin{tabular}{cccccccccccccccc}
\hline \multirow{2}{*}{ Sub-layers } & $0201-$ & $0202-$ & $0203-$ & $0204-$ & $0205-$ & $0206-$ & $0207-$ & $0301-$ & $0302-$ & $0303-$ & $0304-$ & $0305-$ & $0306-$ & $0307-$ & 0308 \\
0306 & 0307 & 0308 & -0309 \\
\hline \multirow{2}{*}{ Drill-in ratio, \% } & 0202 & 0203 & 0204 & 0205 & 0206 & 0207 & 0301 & 0302 & 0303 & 0304 & 0305 & 0306 \\
\hline
\end{tabular}

Based on the data of Table 3, the contrast sections of coefficient of variation and breakthrough coefficient are plotted in Fig. 3 and Fig. 4 respectively. It is obvious that the heterogeneities of sub-layers 0201, 0202, 0308 and 0309 are stronger than other sub-layers. 


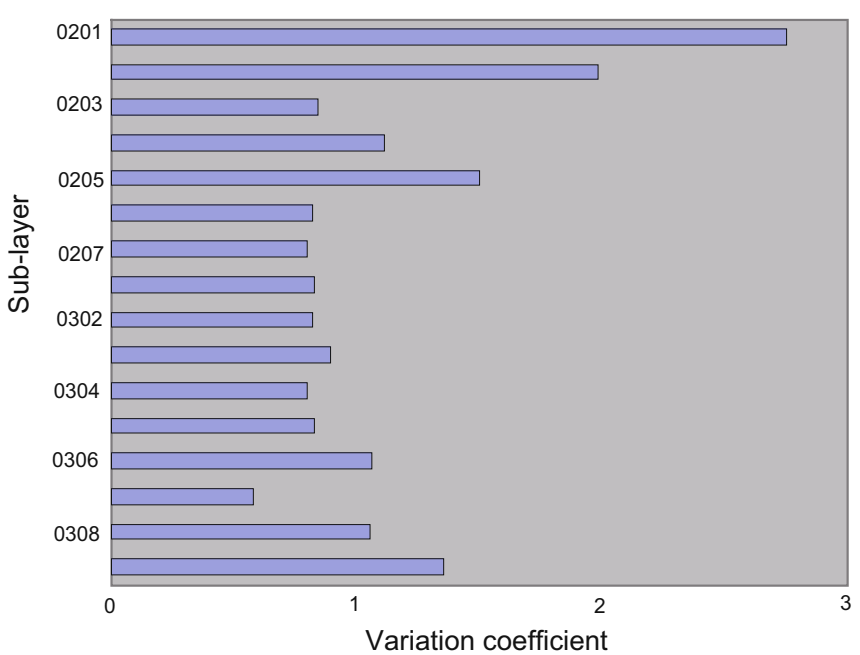

Fig. 3 Coefficient of variation of different sublayers

\subsubsection{Spatial heterogeneity of reservoir}

Spatial heterogeneity describes the heterogeneity controlled by spatial variation of reservoir beds, including spatial distribution, size and connectivity, as well as the variation of porosity and permeability of sand bodies(Zhang, 1996). It is mostly controlled by sedimentary facies.

The sedimentary environment determines the distribution of sand bodies, which in turn is the main element controlling the distribution of oil and gas (Fisher and Knipe, 2001). During the sedimentary period of the 3 and 2 sands, the sediments mainly came from the Luxi Uplift in the northeast,

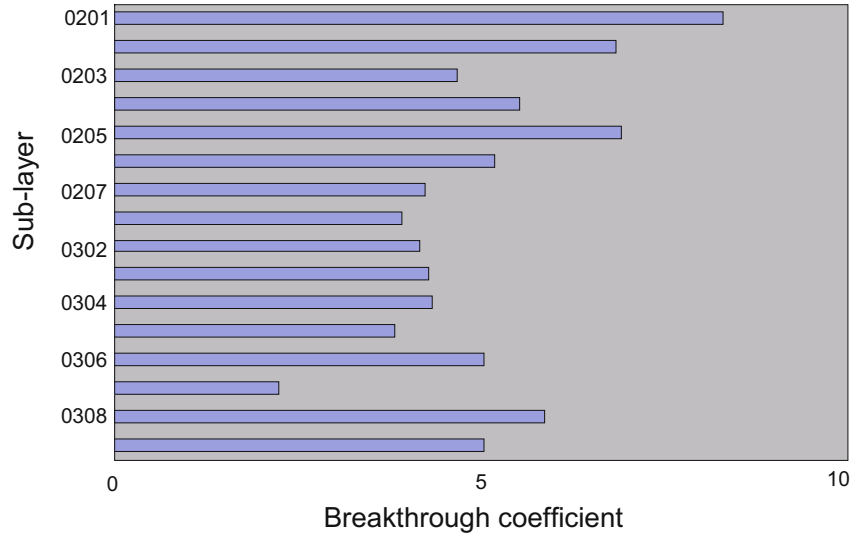

Fig. 4 Breakthrough coefficient of different sublayers

so the distribution of sand bodies extended in the northeastsouthwest direction. According to the development of sedimentary microfacies, the orientation of distributary channels also extended in the same direction. Frequent changes and bifurcations of channels generated variation in the distribution of sand bodies, resulting in different reservoir bed qualities of each sub-layer on the plane. Therefore the spatial distribution of porosity and permeability is heterogeneous (Zhang et al, 2007). The statistical data of porosities of the $2+3$ sands are shown in Table 5 .

Based on the analysis of the areal distribution map of porosities (Fig.5, Fig. 6), the isolines of porosity are dense, especially around some wells, e.g. around Well 2-8 in the

Table 5 Stratistical data of porosities of $2+3$ sands, upper second member, Shahejie Formation

\begin{tabular}{ccccccccccccccccc}
\hline Sub-layer & 0201 & 0202 & 0203 & 0204 & 0205 & 0206 & 0207 & 0301 & 0302 & 0303 & 0304 & 0305 & 0306 & 0307 & 0308 & 0309 \\
\hline $\begin{array}{c}\text { Maximum } \\
\text { porosity }\end{array}$ & 28.5 & 29.2 & 39.65 & 37.3 & 30 & 49.15 & 39.5 & 52.5 & 38.25 & 33.3 & 39.45 & 30 & 30 & 30 & 29.7 & 28.3 \\
\hline $\begin{array}{c}\text { Minimum } \\
\text { porosity }\end{array}$ & 8.3 & 4.5 & 10.65 & 9.3 & 9.6 & 12.5 & 2 & 11.3 & 13.1 & 11.8 & 12.1 & 11 & 11.6 & 12.2 & 10.8 & 11.2 \\
\hline $\begin{array}{c}\text { Mean } \\
\text { porosity }\end{array}$ & 13.7 & 15.3 & 23.5 & 22.97 & 20.35 & 24.38 & 23.6 & 24.36 & 24.51 & 23.69 & 23.99 & 23.68 & 23.2 & 25 & 21.8 & 20 \\
\hline
\end{tabular}

areal distribution map of porosities of the sand 2, around Well 3-106 in the areal distribution map of porosities of the sand 3. Around these wells, the value of porosity decreases quickly, which reflects that the spatial heterogeneity belongs to the type of strong heterogeneity. At the same time, the porosities of most wells in the western part are larger than $20 \%$, according to the criteria for classifying and evaluating detrital reservoir beds (Table 6), such porosities belong to medium

Table 6 Criteria for classifying and evaluating detrital reservoir beds

\begin{tabular}{ccccc}
\hline Category & $\begin{array}{c}\text { High porosity and } \\
\text { permeability }\end{array}$ & $\begin{array}{c}\text { Medium porosity and } \\
\text { permeability }\end{array}$ & $\begin{array}{c}\text { Low porosity and } \\
\text { permeability }\end{array}$ & $\begin{array}{c}\text { Ultra-low porosity and } \\
\text { permeability }\end{array}$ \\
\hline Porosity, $\%$ & $\geq 25$ & $15-25$ & $10-15$ & $<10$ \\
Permeability, $\times 10^{-3} \mu \mathrm{m}^{2}$ & $\geq 500$ & $10-500$ & $1-10$ & $<1$ \\
\hline
\end{tabular}


porosity (Xie and Zhang, 2007).

In light of the analysis of the areal distribution map of permeabilities (Fig. 7, Fig. 8), the isolines of permeability are

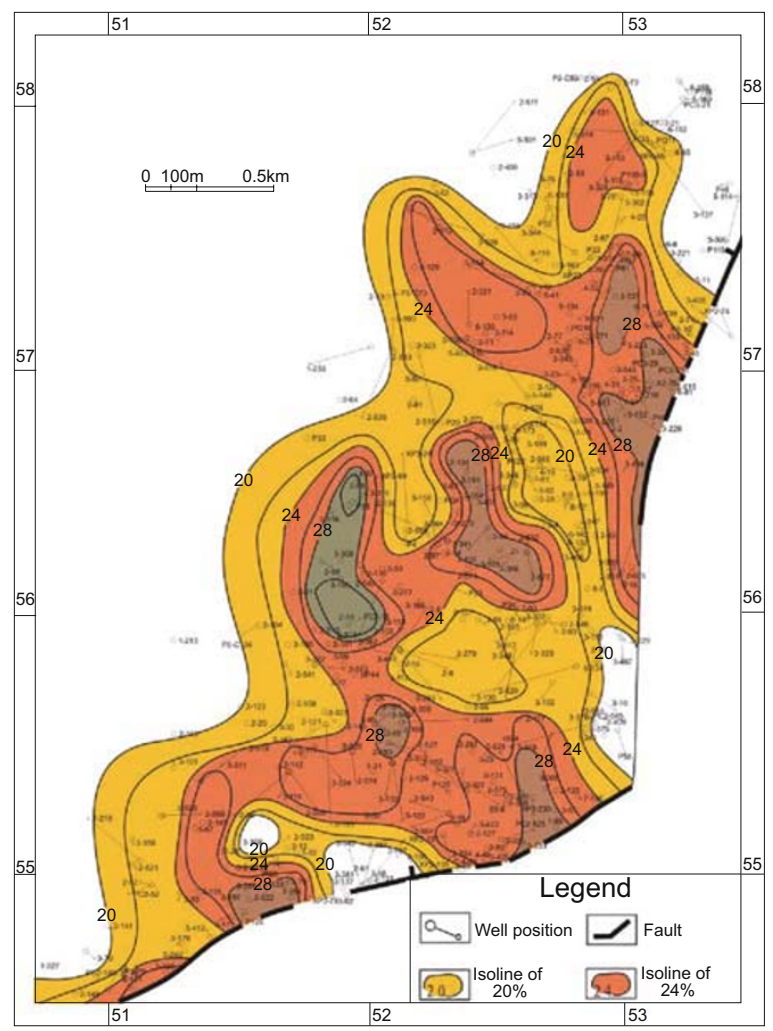

Fig. 5 Areal distribution map of porosities of sand 2

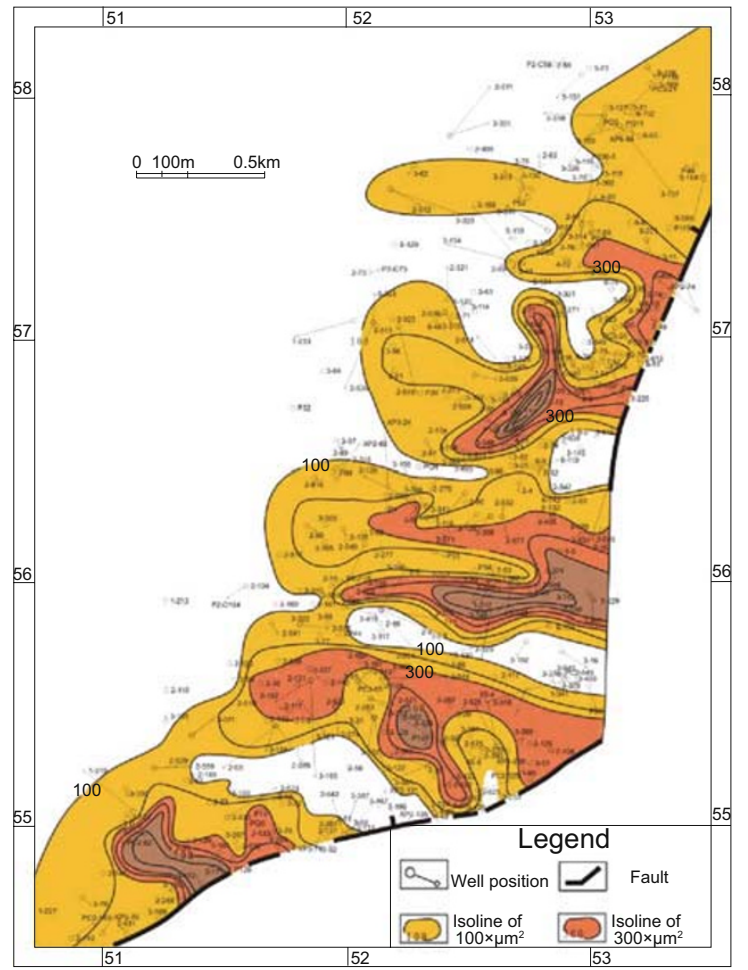

Fig. 7 Areal distribution map of permeabilities of sand 2 also dense; the permeabilities of most wells in the western part are greater than $100 \times 10^{-3} \mu^{2}$. According to the criteria for classifying and evaluating detrital reservoir beds (Table 6), such permeabilities belong to medium permeability.

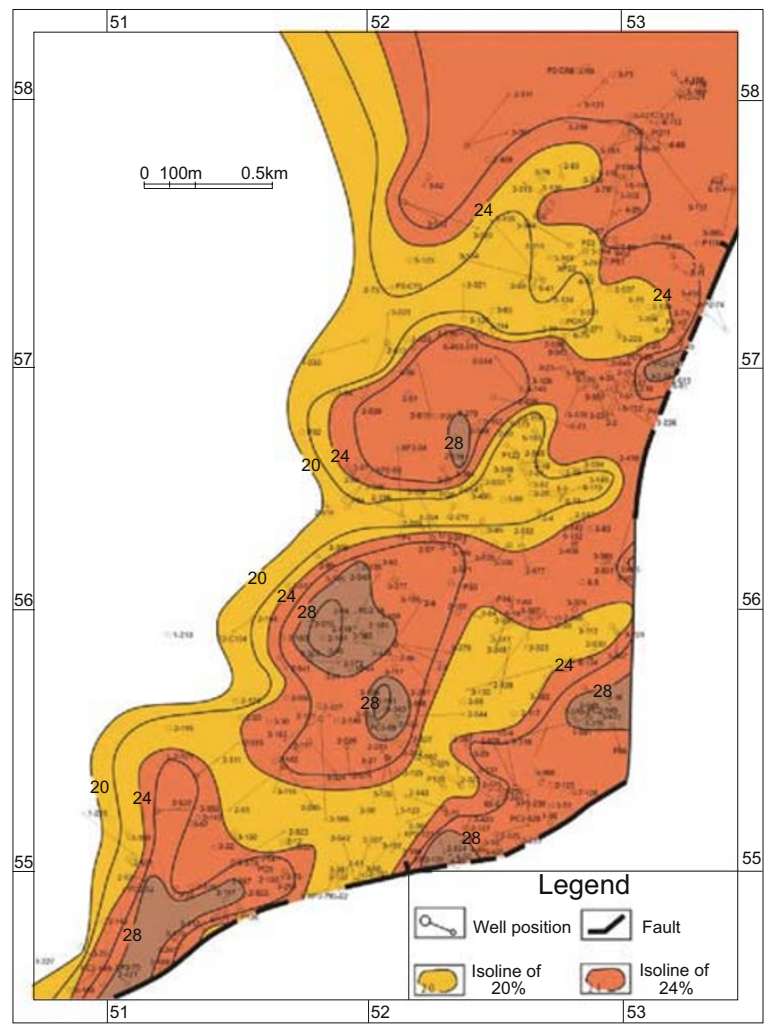

Fig. 6 Areal distribution map of porosities of sand 3

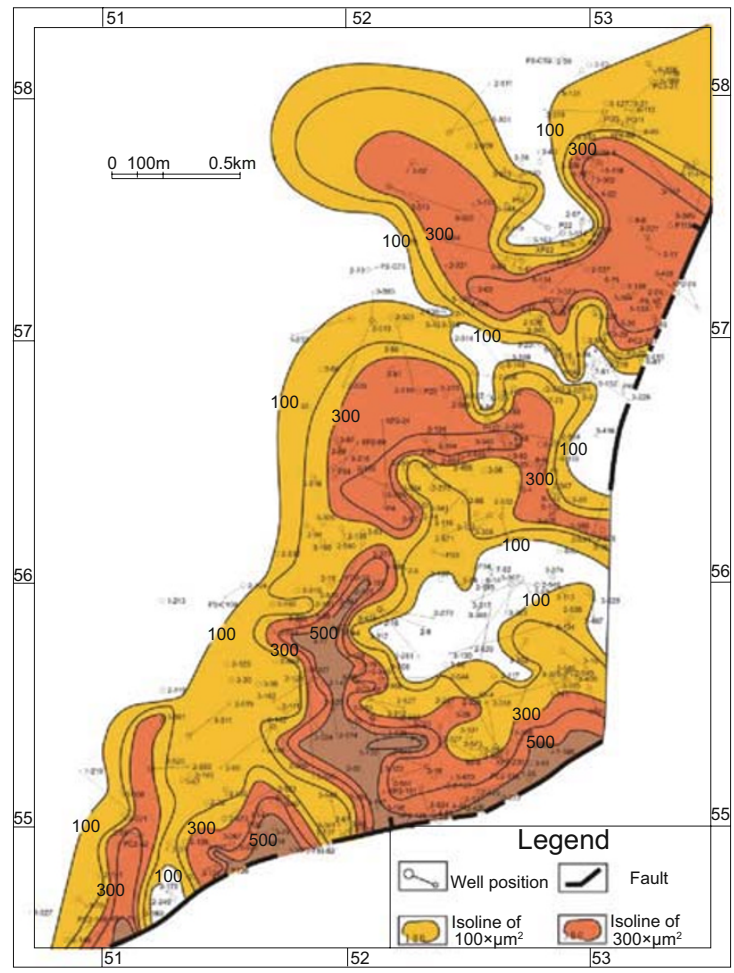

Fig. 8 Areal distribution map of permeabilities of sand 3 


\subsection{Interlayers and seal layers}

3.2.1 Formation types of interlayers and seal layers of $2+3$ sands

Observation of core samples of the $2+3$ sands from multiple cored wells and the data of well-logging, e.g. SP, $\mathrm{MR}$, and GR indicated that interlayers can be classified into three types (Wang and Zhang, 1996): muddy interlayer, silty sand interlayer and calcareous cemented interlayer, and seal layers could be classified into three types: uniformly distributed seal layer, streak-like distributed seal layer and fragmentary seal layer.

Interlayers and seal layers of the $2+3$ sands were mainly developed in three sedimentary micro-environments: proximal overbank, distal overbank, and basinal zone (Zhu et al, 2004).

The proximal overbank microfacies were located on both sides or on the front edge of the distributary channels, and were developed when the flood in channels spread over in flood periods. The components are mainly silty sand, with a high content of mud. The sedimentary architectures are mainly the alternations of light-brown or grayish green mudstone and silty sandstone. The distal overbank microfacies were developed on the front edge of the proximal overbank, and the sediments are mainly alternations of silty sandstone, pelitic siltstone and light brown mudstone, with a high content of mud. The basinal zone microfacies were developed on the plain in front of the distal overbank. Their lithology is mainly light brown and grayish green mudstone, alternating with thin pelitic siltstone (Sean and Henrik, 1993). 3.2.2 Areal distribution of seal layers

Table 7 Statistical data of seal layers in $2+3$ sands upper second member, Shahejie Formation

\begin{tabular}{cccccccccccccccc}
\hline Sub-layers & $\begin{array}{c}0201- \\
0202\end{array}$ & $0202-$ & $0203-$ & $0204-$ & $0205-$ & $0206-$ & $0207-$ & $0301-$ & $0302-$ & $0303-$ & $0304-$ & $\begin{array}{c}0305- \\
0306\end{array}$ & $\begin{array}{c}0306- \\
0307\end{array}$ & $\begin{array}{c}0307- \\
0308\end{array}$ & $\begin{array}{c}0308- \\
0309\end{array}$ \\
\hline Max, m & 9.1 & 6.4 & 6.6 & 8.5 & 8.6 & 6.6 & 7.2 & 6.1 & 6.4 & 10.8 & 9.5 & 6.8 & 6.4 & 6 & 9 \\
\hline Min, m & 0.2 & 0.1 & 0.1 & 0.2 & 0.2 & 0.2 & 0.2 & 0.1 & 0.2 & 0.2 & 0.2 & 0.2 & 0.3 & 0.2 & 0.5 \\
\hline Mean, m & 2.03 & 1.89 & 2.23 & 1.89 & 2.55 & 1.38 & 1.85 & 1.44 & 1.74 & 1.93 & 1.5 & 1.48 & 1.50 & 1.89 & 1.76 \\
\hline drill-in ratio, \% & 78.1 & 79.5 & 82.4 & 59.2 & 81.4 & 62.4 & 72.4 & 59.2 & 59.5 & 71.9 & 72.2 & 70.5 & 76.8 & 77.3 & 70.3 \\
\hline
\end{tabular}

According to the analysis, the distribution of seal layers between sub-layers was controlled by the sedimentary microfacies of proximal overbank and distal overbank (Zhang et al, 2007), which determined the vertical and spatial features of seal layers.

In the whole, the mean thickness of seal layers is larger, and the thickness is always between 0 and 5 meters; the drillin ratio of seal layers in each sub-layer is higher (Table 7). Some seal layers are up to 8 meters in some places. The drillin ratio of seal layers between 0 and 5 meters is more than $50 \%$, because of the specific genetic environments. The seal layers are thicker in the overbank zone, while thinner in the zone where the channels were concentrated.

The areal distribution of seal layers of $\mathrm{S}_{2}{ }^{1}-\mathrm{S}_{2}{ }^{2}, \mathrm{~S}_{2}{ }^{6}-\mathrm{S}_{2}{ }^{7}$, $\mathrm{S}_{3}{ }^{1}-\mathrm{S}_{3}{ }^{2}, \mathrm{~S}_{3}{ }^{8}-\mathrm{S}_{3}{ }^{9}$ is plotted in Fig. 9, Fig. 10, Fig. 11, and Fig. 12 respectively. Based on the analysis of these plots, in the whole western part, thick seal layers are distributed in the northeast and middle. The thicknesses are between 5 and 6 meters, decreasing in the southwest direction, down to less than 3 meters. This situation is related to the supply of sediment from the Luxi Uplift in the northeast.

\subsubsection{Areal distribution of interlayers}

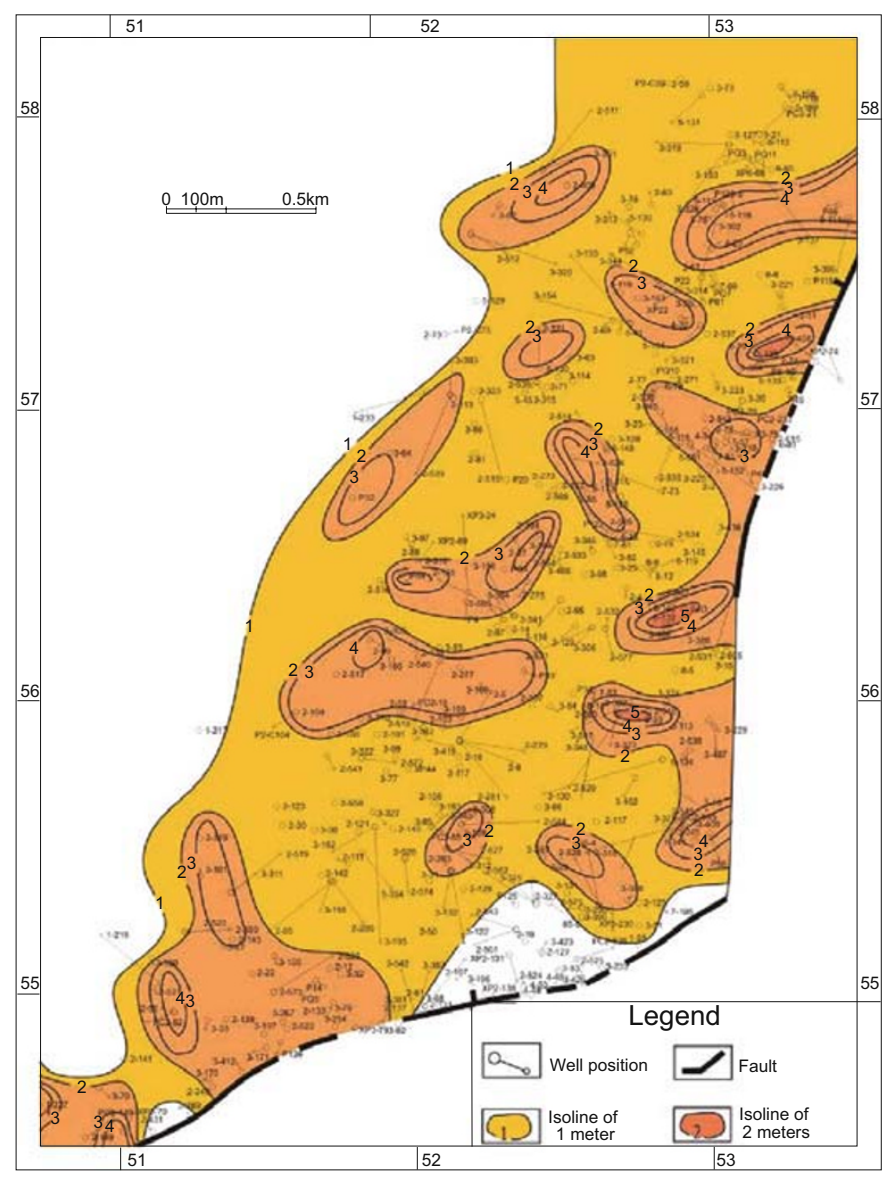

Fig. 9 Areal distribution of seal layers in $\mathrm{S}_{2}{ }^{1}$ and $\mathrm{S}_{2}{ }^{2}$ 


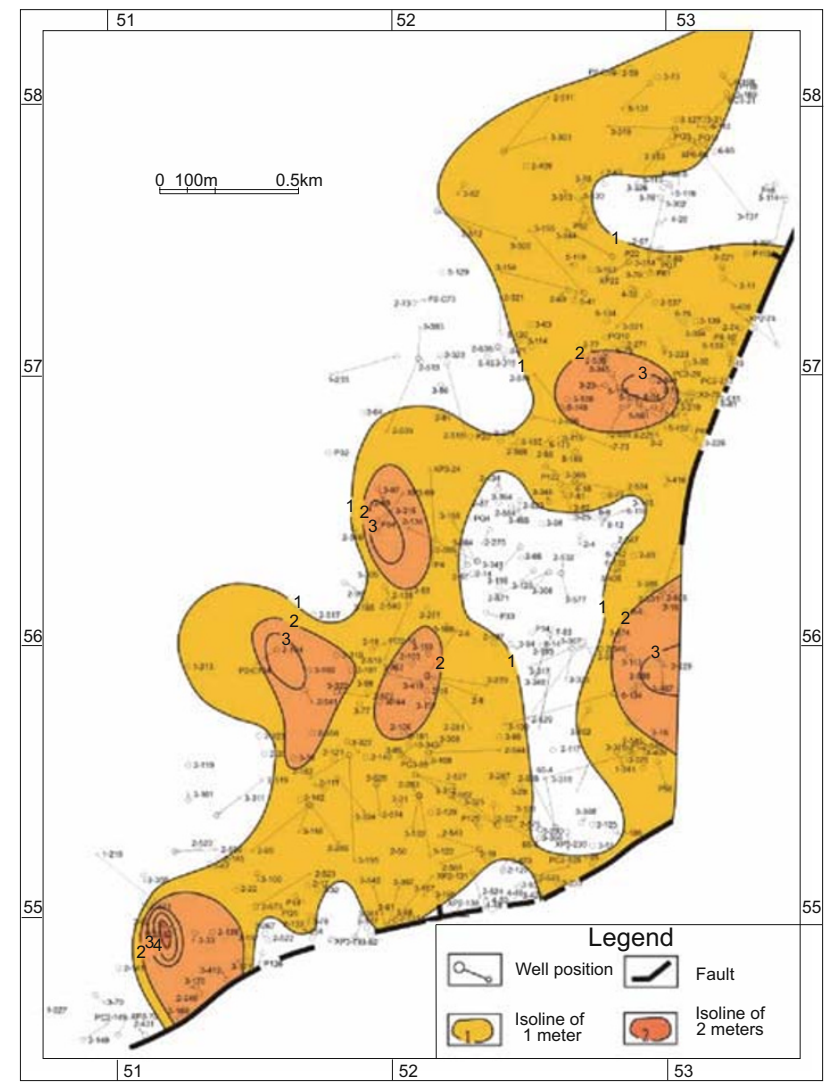

Fig. 10 Areal distribution of seal layers in $\mathrm{S}_{2}{ }^{6}$ and $\mathrm{S}_{2}{ }^{7}$

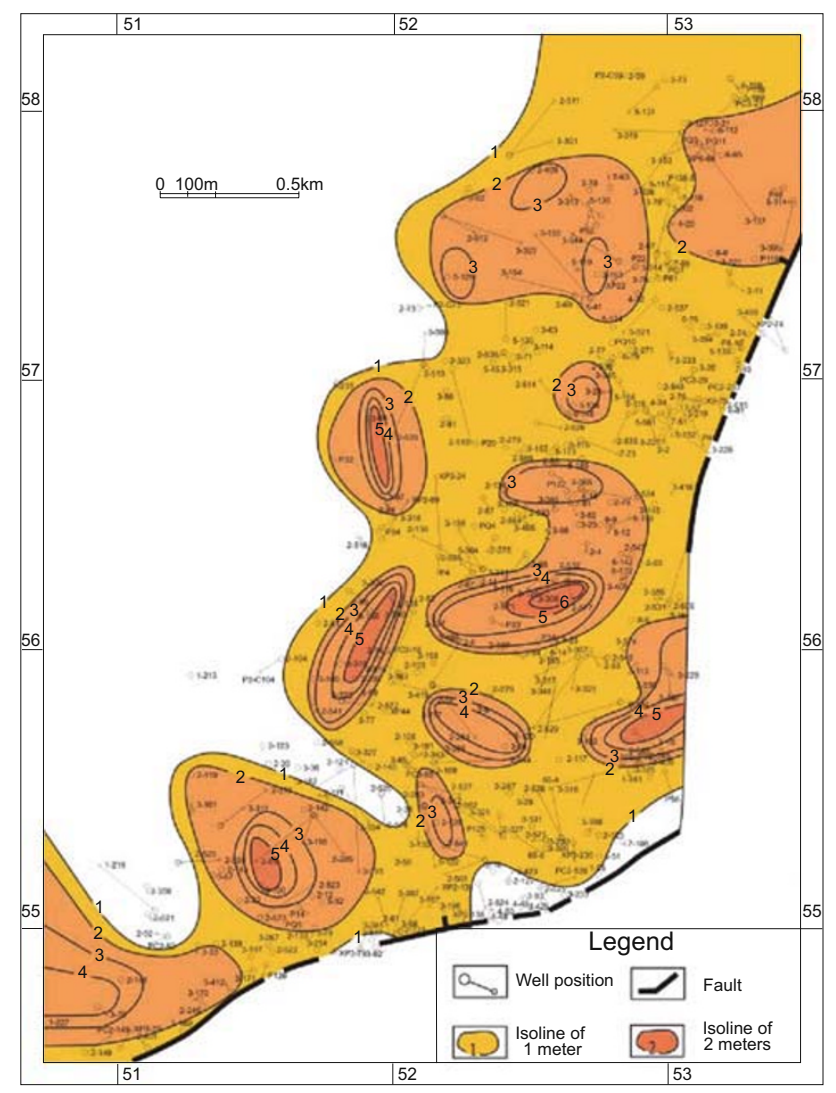

Fig. 12 Areal distribution of seal layers in $\mathrm{S}_{3}{ }^{8}$ and $\mathrm{S}_{3}{ }^{9}$

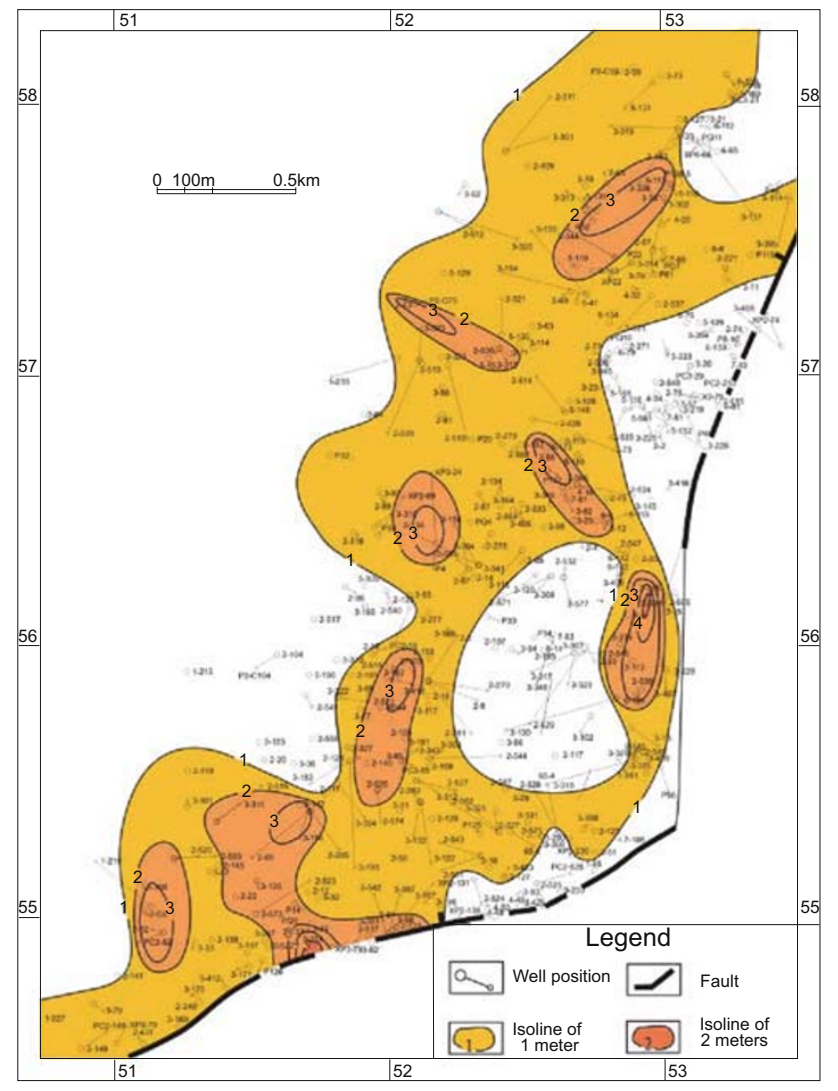

Fig. 11 Areal distribution of seal layers in $\mathrm{S}_{3}{ }^{1}$ and $\mathrm{S}_{3}{ }^{2}$

From the statistical data of interlayers (Table 8), the thickness of interlayers is thinner than the thickness of seal layers, and is between 1.33 and 3 meters. The spatial distributions of interlayer of $\mathrm{S}_{2}{ }^{1}, \mathrm{~S}_{2}{ }^{7}, \mathrm{~S}_{3}{ }^{1}$ and $\mathrm{S}_{3}{ }^{8}$ are plotted in Fig. 13, Fig.14, Fig. 15, and Fig.16 respectively.

On the basis of these plots, the thicknesses of interlayers are apparently thinner than those of seal layers. The thick interlayers are mainly formed in the northeastern and middle parts, and are mostly between 3 and 5 meters. The interlayers less than 1 meter are located in the southwestern and southeastern parts, decreasing from northeast to southwest. The reason is that the distributary channels were more welldeveloped in the northeastern and middle parts than the southwestern part which is related to the development of proximal overbank and distal overbank deposits from the northeast. 
Table 8 Statistical data of interlayers of $2+3$ sands, upper second member, Shahejie Formation

\begin{tabular}{|c|c|c|c|c|c|c|c|c|c|c|c|c|c|c|c|c|}
\hline Sub-layers & 0201 & 0202 & 0203 & 0204 & 0205 & 0206 & 0207 & 0301 & 0302 & 0303 & 0304 & 0305 & 0306 & 0307 & 0308 & 0309 \\
\hline Max, m & 8.5 & 5 & 5.5 & 5.5 & 5.4 & 7.1 & 5 & 5.6 & 5.8 & 5.7 & 4.9 & 4 & 4.6 & 5.6 & 8.5 & 10 \\
\hline Min, $\mathrm{m}$ & 0 & 0 & 0 & 0.1 & 0 & 0 & 0 & 0.2 & 0.4 & 0.2 & 0 & 0.4 & 0.6 & 0.3 & 0.4 & 0.4 \\
\hline Mean, m & 2.13 & 1.8 & 1.36 & 1.33 & 20.7 & 1.65 & 1.35 & 1.83 & 1.68 & 1.63 & 1.59 & 1.3 & 1.45 & 1.38 & 1.79 & 2.72 \\
\hline
\end{tabular}

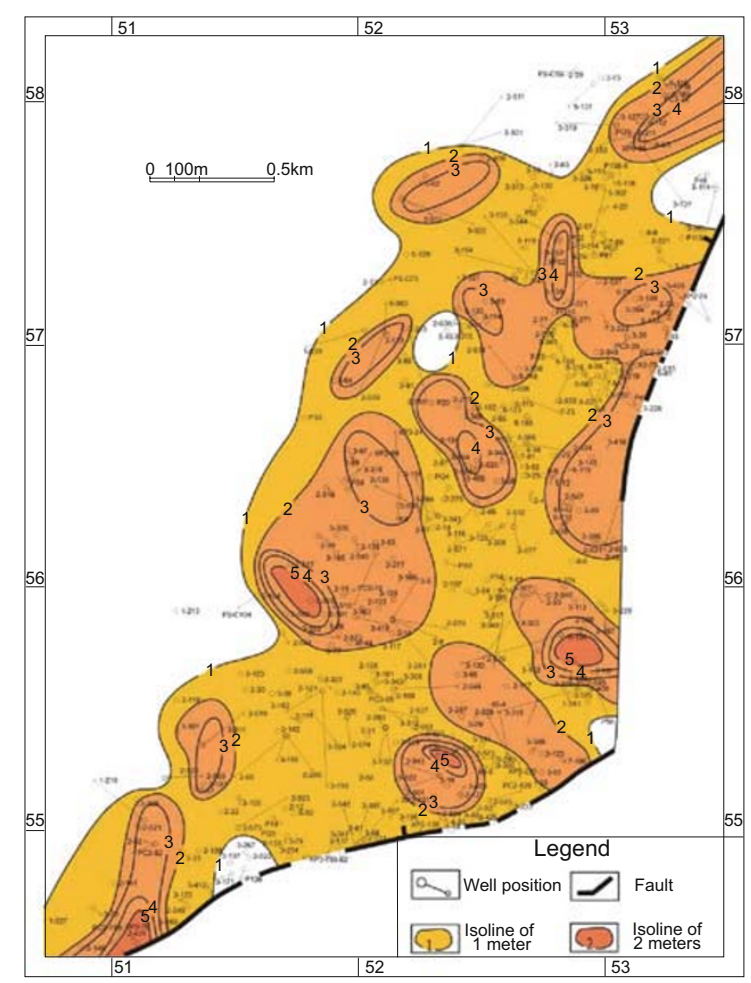

Fig. 13 Areal distribution of interlayers of 1 st sub-layer of sand 2

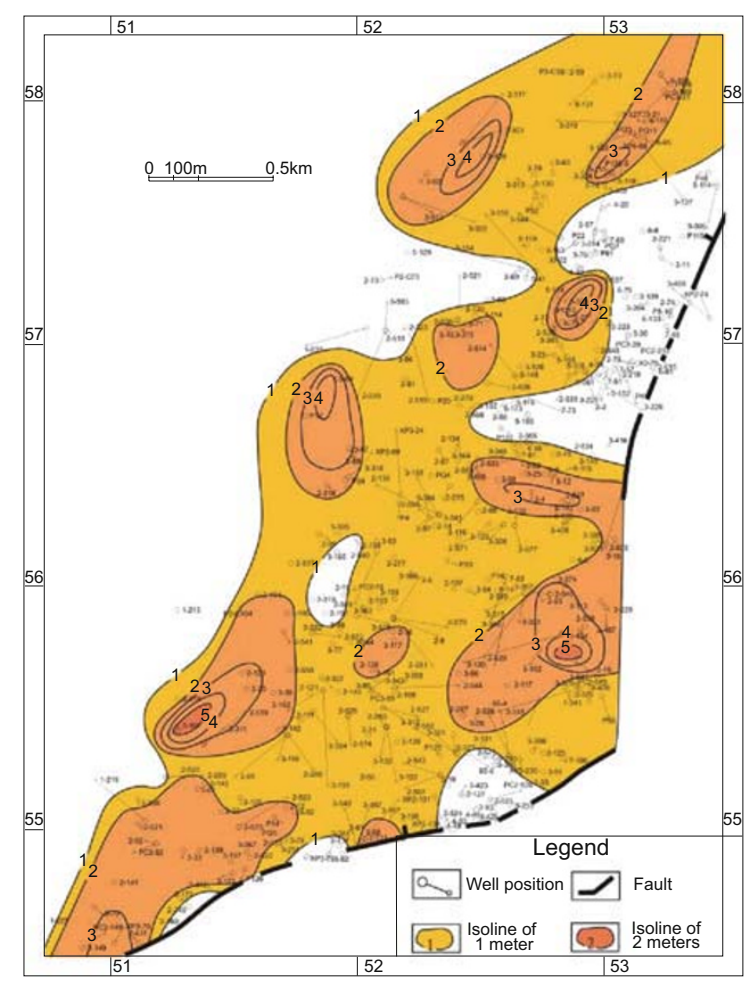

Fig. 15 Areal distribution of interlayers of 1st sub-layer of sand 3

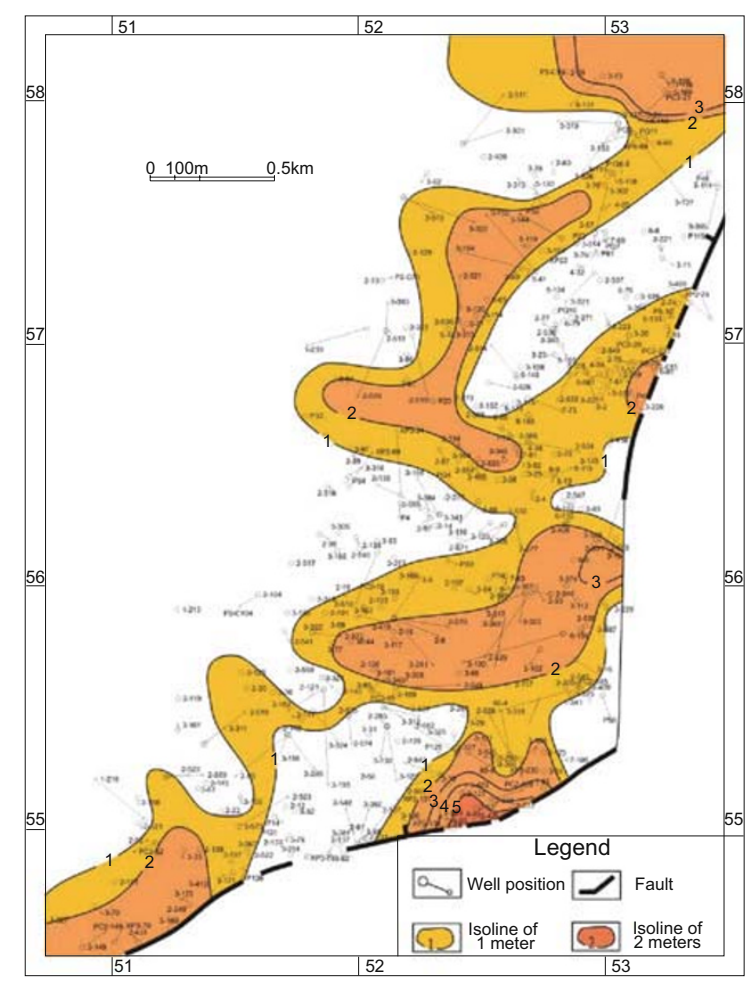

Fig. 14 Areal distribution of interlayers of 7 th sub-layer of sand 2

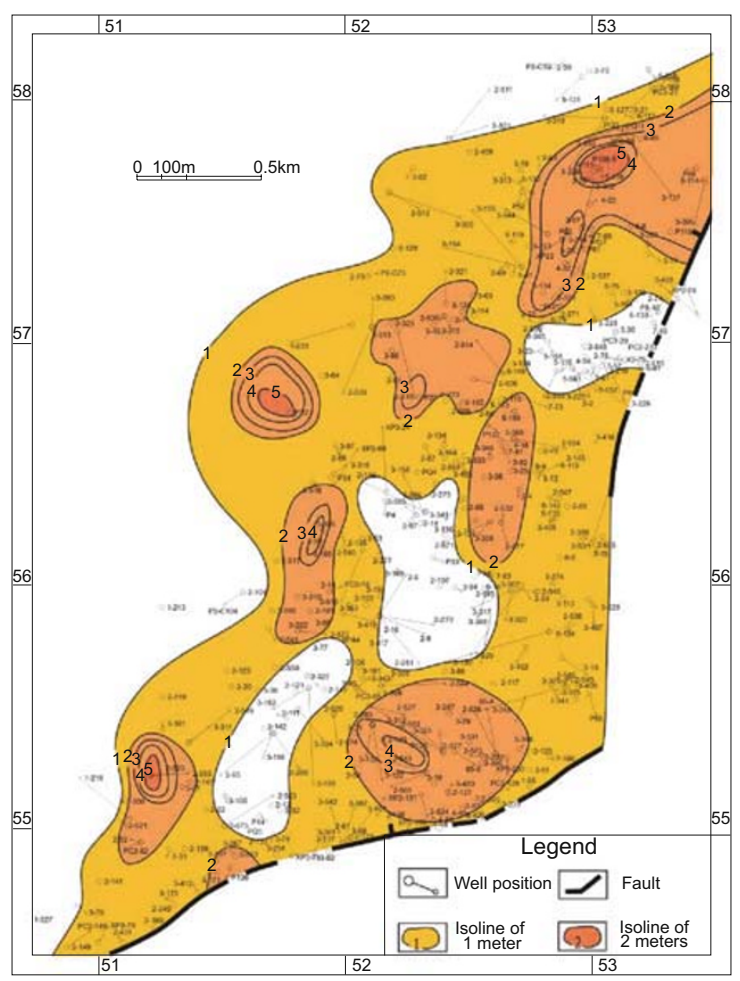

Fig. 16 Areal distribution of interlayers of 8 th sub-layer of sand 3 


\section{Conclusions}

1) The intra-layer heterogeneity and inter-layer heterogeneity of the $2+3$ sands, Shahejie Formation in the Pucheng Oilfield mainly belong to the severely heterogeneous category.

2) Spatial heterogeneity is mainly controlled by sedimentary facies, and the differentiation of microfacies caused the varying degrees of heterogeneity. Additionally, the heterogeneity in the northern and middle parts is higher than that in the southern part.

3) Observation of core samples of the $2+3$ sands from multiple cored wells and the data of well-logging, e.g. SP, MR, and GR indicated that interlayers could be classified into three types: muddy interlayers, silty sand interlayers and calcareous cemented interlayers and seal layers could be classified into three types: uniformly distributed seal layers, streak-like distributed seal layers, and fragmentary seal layers.

4) Interlayers and seal layers are thicker in the northeastern and middle parts, and thinner in the southwestern part.

\section{References}

Fisher Q J and Knipe R J. The permeability of faults within siliciclastic petroleum reservoirs of the North Sea and Norwegian Contimental Shelf. Marine and Petroleum Geology. 2001. 18: 1063-1081

Ji J, Zhong J H, Mao L H and Fu J. Study on reservoir heterogeneity of the upper ES2 ${ }^{\wedge} 2+3$ in the east area of Pucheng Oilfield. Petroleum Geology and Engineering. 2007. 21(5): 23-26 (in Chinese)

Li J and Li H. Research of remaining oil of the second member in Shahejie Formation in the west of Pucheng Oilfield. Exploration and Exploitation of Oil. 2003. 30(6): 98-101 (in Chinese)

Liu G Q, Zhang A W and Li J G. The application of reservoir description and remaining oil exploitation in fault block oil reservoir. The Journal of Chongqing Petroleum Institute. 2001. 3(2): 19-22 (in Chinese)

Qin L J and Zhang J L. Reservoir evaluation of the Upper ES2 ${ }^{\wedge} 2+3$ in the south area of Pucheng Oilfield. Journal of Xi' an ShiYou University. 2007. 22(4): 40-46, 52 (in Chinese)

Sean B K and Henrik O. Terminal fans - a review with reference to Devonian examples. Sedimentary Geology. 1993. 85: 339-374

Stanistreet I G and McCarthy T S. The Okavango Fan and the classification of subaerial fan systems. Sedimentary Geology .1993. $85: 115-133$

Wang L Ch and Zhang J L. Sedimentary Environment and Facies. Petroleum Industry Press. 1996.14-32 (in Chinese)

Xia W R, Zhang Z F and Chen S Q. Development Geology of Oil and Gas Field. Petroleum Industry Press. 1999. 12-20 (in Chinese)

Xie J and Zhang W. Discussion on particularities of reservoir heterogeneity in later development of reservoirs. Journal of China University of Geosciences. 2007. Vol.18 Special Issue: 320-322 (in Chinese)

Zhang J L, Jia Y and Du G L. Diagenesis and its effect on reservoir quality of silurian sandstones, Tabei Area, Tarim Basin. Petroleum Science. 2007. 4(3): 1-13 (in Chinese)

Zhang J L and Chang X C. Petroleum Geology. Petroleum Industry Press. 2004. 61-123 (in Chinese)

Zhang J L, Dai C Q and Zhang X H. Terminal fan-a type of sedimentation ignored in China. Geological Review. 2007. 53(2): 170-179 (in Chinese)

Zhang J L. Study on Development Geology of Sandstone Reservoir. Science and Technology Publish House of Shanxi. 1996. 22-33 (in Chinese)

Zhou Y and Li D L. The distribution of remaining oil in the second member of the Shahejie Formation, Pucheng Oilfield. Oil and Gas Geology. 2001. 22 (3): 253-255, 260 (in Chinese)

Zhu D Y, Hu W X, Cao X W and Chen G C. Divide of type and research of distribution of seal and interlayer in Linnan Oilfield. GeoscienceJournal of China University of Geosciences. 2004. 29(2): 211-218, 223 (in Chinese)

(Edited by Yang Lei) 